\title{
Author Spotlight: Andrew A. Li
}

\section{Andrew A. Li ${ }^{1}$}

Accepted: 5 February 2021 / Published online: 21 February 2021

(C) The Author(s), under exclusive licence to Springer Science+Business Media, LLC part of Springer Nature 2021

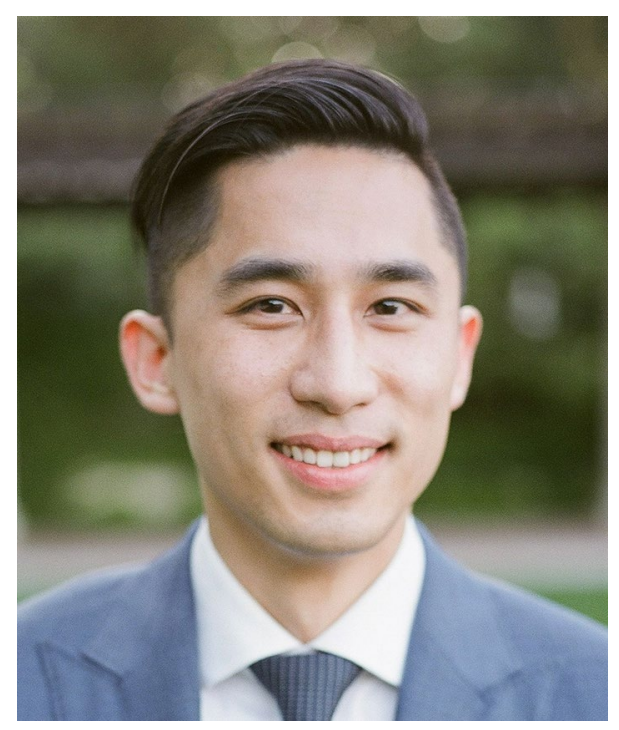

Andrew A. Li, MD is a second-year gastroenterology fellow at Stanford University. He received his undergraduate degree from Princeton University and his medical degree from Harvard Medical School in the Harvard-MIT Health Sciences and Technology program. He completed an internal medicine residency at Stanford University. His clinical and research interests are in advanced endoscopy and translational approaches applied to gastrointestinal cancers. After completing fellowship, he intends to pursue training in advanced endoscopy and a career in academic medicine.

Publisher's Note Springer Nature remains neutral with regard to jurisdictional claims in published maps and institutional affiliations.

Andrew A. Li

andrewli@stanford.edu

1 Division of Gastroenterology and Hepatology, Stanford University School of Medicine, Stanford, CA, USA 